\title{
Research
}

\section{Age related, structured educational programmes for the management of atopic dermatitis in children and adolescents: multicentre, randomised controlled trial}

Doris Staab, Thomas L Diepgen, Manigé Fartasch, Jörg Kupfer, Thomas Lob-Corzilius, Johannes Ring, Sibylle Scheewe, Reginald Scheidt, Gerhard Schmid-Ott, Christina Schnopp, Rüdiger Szczepanski, Thomas Werfel, Marita Wittenmeier, Ulrich Wahn, Uwe Gieler

\begin{abstract}
Objective To determine the effects of age related, structured educational programmes on the management of moderate to severe atopic dermatitis in childhood and adolescence.

Design Multicentre, randomised controlled trial.

Setting Seven hospitals in Germany.

Participants Parents of children with atopic dermatitis aged 3 months to 7 years $(n=274)$ and 8 - 12 years $(n=102)$, adolescents with atopic dermatitis aged $13-18$ years $(n=70)$, and controls $(n=244, n=83$, and $n=50$, respectively).

Interventions Group sessions of standardised intervention programmes for atopic dermatitis once weekly for six weeks or no education (control group).

Main outcome measures Severity of eczema (scoring of atopic dermatitis scale), subjective severity (standardised questionnaires), and quality of life for parents of affected children aged less than 13 years, over 12 months.

Results Significant improvements in severity of eczema and subjective severity were seen in all intervention groups compared with control groups (total score for severity: age 3 months to 7 years $-17.5,95 \%$ confidence intervals -19.6 to $-15.3 v-12.2,-14.3$ to -10.1 ; age 8 - 12 years $-16.0,-20.0$ to $-12.0 v-7.8,-11.4 ;-4.3$; and age $13-18$ years -19.7 , -23.7 to $-15.7 v-5.2,-10.5$ to 0.1 ). Parents of affected children aged less than 7 years experienced significantly better improvement in all five quality of life subscales, whereas parents of affected children aged 8-12 years experienced significantly better improvement in three of five quality of life subscales. Conclusion Age related educational programmes for the control of atopic dermatitis in children and adolescents are effective in the long term management of the disease.
\end{abstract}

\section{Introduction}

Atopic dermatitis is a chronically relapsing, inflammatory skin disease affecting up to a fifth of schoolchildren. ${ }^{1}$ Recent studies suggest that this prevalence is increasing in industrialised countries. ${ }^{2}$ Atopic dermatitis commonly begins in infancy or early childhood, and the symptoms of itching, scratching, and sleeplessness can place a burden on the whole family. ${ }^{3}$ Lack of information, overstrain, helplessness, and lack of confidence in medical treatment lead to suboptimal management of the disease and increasing use of healthcare resources, including alternative therapies.
Educational programmes aim to empower patients and carers in solving the problems arising from chronic diseases, ${ }^{4}$ and meta-analysis of results has highlighted the need for standardised methods so that improvements in self management of chronic disease can be more accurately assessed. ${ }^{56}$ Although several educational interventions have been developed for adults with atopic dermatitis, the literature on educational programmes for children and their parents is sparse. ${ }^{7}$ In addition, studies have not used the type of standardised, structured intervention that is proving highly beneficial in the management of other chronic atopic conditions in children, such as asthma. ${ }^{8}$

Our study, the German atopic dermatitis intervention study, was set up to develop standardised interventions for the self management of atopic dermatitis and to assess their effects. We have used our collective experience and the input from three consensus conferences to define the content and structure of such a programme, including study design and choice of evaluation instruments. Here we report data, stratified into three age groups, collected from 992 families with children aged 3 months to 18 years with atopic dermatitis, within a multicentre, randomised controlled study. We determined the long term effect of age related, structured educational programmes on the control of moderate to severe atopic dermatitis in childhood and adolescence by assessing changes in disease severity, itch, and parents' quality of life over 12 months.

\section{Participants and methods}

The three participating groups were parents of children with atopic dermatitis aged 3 months to 7 years and 8-12 years and adolescents with atopic dermatitis aged 13-18 years (table 1). Participants were recruited from seven centres in Germany: three children's hospitals (Berlin, Osnabrück, and Cologne), three hospitals specialising in dermatology (Munich, Erlangen, and Hannover), and one department of psychosomatic medicine (Giessen). Atopic dermatitis was diagnosed by dermatologists or paediatricians. The inclusion criteria were diagnosis of atopic dermatitis according to the criteria of Hanifin and Rajka, ${ }^{9}$ eczema duration a minimum of at least three months, and a severity of eczema of at least 20 points according to the scoring of atopic dermatitis scale. ${ }^{10}$ Exclusion criteria were other acute or

Study centres and members are on bmj.com 
Table 1 Structure and content of educational programme aimed at parents of children with atopic dermatitis and adolescents with atopic dermatitis

\begin{tabular}{|c|c|c|c|c|c|}
\hline \multirow[b]{2}{*}{ Session } & \multirow[b]{2}{*}{ Trainer } & \multicolumn{3}{|c|}{ Target groups } & \multirow[b]{2}{*}{ Topics } \\
\hline & & 3 months to 7 years & 8-12 years & 13-18 years & \\
\hline 1 & $\begin{array}{l}\text { Paediatrician or dermatologist } \\
\text { and psychologist }\end{array}$ & Parents & Parents and children* & $\begin{array}{l}\text { Adolescents (parents } \\
\text { optional) }\end{array}$ & $\begin{array}{l}\text { Introduction round, basic medical information about atopic } \\
\text { dermatitis, introduction of relaxation technique }\end{array}$ \\
\hline 2 & Psychologist & Parents & Parents and children & $\begin{array}{l}\text { Adolescents (parents } \\
\text { optional) }\end{array}$ & $\begin{array}{l}\text { Stress management, dealing with itching and scratching and sleep } \\
\text { disturbances }\end{array}$ \\
\hline 3 & Nurse & Parents & Parents and children & Adolescents & Recognition and avoidance of trigger factors, daily skin care \\
\hline 4 & Paediatrician or dermatologist & Parents & Parents and children & Adolescents & Stage related treatment of symptoms, unconventional therapies \\
\hline 5 & Dietician & Parents & Parents and children & Adolescents & $\begin{array}{l}\text { General child nutrition, food allergies in atopic dermatitis, different } \\
\text { forms of diets }\end{array}$ \\
\hline 6 & $\begin{array}{l}\text { Paediatrician or dermatologist } \\
\text { and psychologist }\end{array}$ & Parents & Parents and children & Adolescents & $\begin{array}{l}\text { Issues of coping; self management plan, problems in transfer to } \\
\text { daily routine }\end{array}$ \\
\hline
\end{tabular}

${ }^{*}$ Courses for parents and children were held in parallel in two rooms; children were educated by same instructor throughout (trained nurse or tutor).

chronic illnesses or psychiatric disorders requiring treatment. A total of 992 patients were eligible and agreed to participate in the study. All participants (parents and adolescents) gave written informed consent.

After one year, 823 participants could be reached for evaluation: dropout rate of $17 \%$ (10\% in the intervention group, $24 \%$ in the control group).

\section{Study design}

The study was designed as a randomised, controlled intervention study. Randomisation was carried out anonymously by an independent study centre in Heidelberg using computer generated random numbers. The randomisation code was concealed in closed envelopes from those entering patients into the study. The treatment programme consisted of six, weekly group sessions (5-8 participants), lasting two hours each. Patients were drawn consecutively from the seven study centres. The patients and their parents in the intervention and control groups were followed up at six (data not shown) and 12 months. The sample size estimation and power calculation was based on the severity of eczema (total on scoring of atopic dermatitis scale) as the primary outcome. With an effect size $d$ of $0.40,{ }^{11} \alpha=5 \%$, and $\beta=20 \%$, we calculated that we would need 125 participants in each group, assuming a $20 \%$ loss during follow-up. No interims analysis was carried out, no stopping rules.

The participants could not be blinded as they were aware that they were receiving education, and it was also not possible for the trainers to be blinded. The scoring of atopic dermatitis scale was measured by investigators who were not actively involved as trainers.

\section{Interventions}

The educational programme was standardised to provide theme centred group training and comprised six, once weekly sessions, lasting two hours each. Parents of affected children aged 3 months to 7 years received education, with the contents of the sessions based on previously reported work. ${ }^{12}$ The parents of affected children aged 8-12 years attended separate educational sessions. Adolescents aged 13-18 years attended educational sessions tailored to their needs. ${ }^{13}$ These sessions covered medical, nutritional, and psychological issues, and were carried out by a multiprofessional team of dermatologists or paediatricians, psychologists, and dietitians, who had undergone a 40 hour training programme to qualify as trainers (see table 1 ). The contents and structure of the programme and didactic methods were discussed and worked out by an interdisciplinary consensus group over two years before starting the programme.

A manual specified the content of each session, and participants were given handouts summarising the timetable and the most important points of the sessions. The sessions also encouraged participants to share personal experiences and to try out newly learned skills.

The educational programme did not contain a therapy mandate, and any topical or systemic individual therapy (for example, prescriptions or specific diets) remained the responsibility of the patients' doctors.

\section{Outcome measures}

The primary end points were the differences in severity of eczema and parents' quality of life between the start of the study (baseline) and follow-up at 12 months.

\section{Severity of eczema}

We graded the severity of eczema using the scoring of atopic dermatitis scale. ${ }^{10}$ This scale is based on the extent of eczema, the morphology of the lesions, and the two subjective items of sleep disturbance during the night and itch. The objective scoring of atopic dermatitis is the total score on the scoring of atopic dermatitis scale minus the scores related to both subjective items.

\section{Subjective severity score}

The subjective severity of eczema was measured using the "skin detective," ${ }^{14}$ a subjective score for severity related to part of the scoring of atopic dermatitis scale. The parents compared the morphology of their child's skin lesions with those of illustrations evaluated by experts. ${ }^{14}$

\section{Itch questionnaires}

We used two standardised questionnaires to measure itching behaviour: JUCKKI, which contains 15 items and is aimed at 8-12 year olds, and JUCKJU, which comprises 18 items and is aimed at 13-18 year olds. ${ }^{15}$ The final versions of these two questionnaires were tested after preliminary studies in a group of 204 children and 168 adolescents. Two-factorial scale solutions resulted for both questionnaires. The two factors covered the areas catastrophisation (negative thoughts on pain that have got out of control) and coping. The internal consistence can be rated satisfactory to good, with values between 0.72 and 0.91 . The questionnaires on itching cognitions provide two age appropriate procedures for children and adolescents with which differential aspects of these constructs can be reliably measured..$^{15}$

\section{Quality of life for parents of children aged less than 13 years}

Parents' quality of life was measured with the German questionnaire "Quality of life in parents of children with atopic dermatitis." This questionnaire was developed as part of the Berlin public health study "Evaluation of an educational programme for parents of children with atopic dermatitis," and has been validated $^{16}$; it consists of 26 items, which can be divided by factor 
analysis into five interpretable subscales: psychosomatic wellbeing, effects on social life, confidence in medical treatment, emotional coping, and acceptance of the disease. Convergent validity of this instrument has been tested. The questionnaire also highlights differences between parents of children with varying degrees of disease severity, which is a prime indicator of clinical relevance. The questionnaire has shown high intraclass coefficients for test retest reliability. The reliability for the subscales was medium to high, which was expressed by a Cronbach's $\alpha$ of between 0.57 and 0.90 . The intercorrelations of the dimensions are moderate $(0.20-0.63)$, which shows that each dimension gives independent information on the respective aspects of quality of life.

\section{Statistical analysis}

All statistical analyses were carried out using SAS. For statistical tests we used non-parametric methods. We used analyses of covariance to compare values at baseline with those at 12 months between the study arms.

\section{Results}

In total, 1010 patients were assessed for eligibility to take part in the study: 645 parents of children with atopic dermatitis aged 3 months to 7 years, 214 parents of affected children aged 8-12 years, and 151 adolescents aged 13-18 years. Of these, 992 participants were randomised (figure). In all age groups the severity of eczema did not differ significantly between the intervention and control groups at baseline (table 2). Additionally, no statistically significant differences were found between the intervention and control participants for all other outcome measures at baseline. After losses during follow-up, the number of participants in the intervention arms was 274 for children aged 3 months to 7 years; 102 for children aged 8-12 years; and 70 for adolescents aged 13-18 years. Comparable numbers in the control groups were 244, 83 , and 50. The clinical characteristics and results of all outcome measures at baseline did not differ significantly between participants lost to follow-up and those remaining.

\section{Severity of eczema according to scoring of atopic dermatitis} scale

At baseline the mean score for severity of eczema was greater than 40 points in the intervention and control groups. At 12
Table 2 Baseline characteristics of groups receiving educational intervention for atopic dermatitis or no education (control)

\begin{tabular}{lcc} 
Variable & Intervention groups & Control groups \\
\hline 3 months to 7 years: & $\mathrm{n}=274$ & $\mathrm{n}=244$ \\
\hline Mean (SD) age (years) & $2.4(1.8)$ & $2.4(1.9)$ \\
\hline No (\%) male & $143(52)$ & $127(52)$ \\
\hline 8-12 years: & $\mathrm{n}=102$ & $\mathrm{n}=83$ \\
\hline Mean (SD) age (years) & $9.5(1.6)$ & $9.5(1.5)$ \\
\hline No (\%) male & $41(40)$ & $40(48)$ \\
\hline 13-18 years: & $\mathrm{n}=70$ & $\mathrm{n}=50$ \\
\hline Mean (SD) age (years) & $14.9(1.7)$ & $14.8(1.7)$ \\
\hline No (\%) male & $29(41)$ & $18(36)$ \\
\hline
\end{tabular}

months' follow-up the severity of eczema had decreased in all groups, but the decrease was significantly greater in the intervention arms (table 3).

\section{Subjective severity score}

Self evaluation of atopic dermatitis by children and adolescents has been shown to be similar to evaluation by experts. In our study the subjective severity score for eczema decreased significantly more in the intervention groups (table 3).

\section{Itching behaviour in 8-12 year olds and 13-18 year olds}

Table 3 shows the results of the subscales of the itch questionnaires in children aged 8 - 12 years and the adolescents at baseline and 12 months' follow-up. In the 8-12 year olds, significantly greater improvements were shown in the intervention group for the subscales catastrophisation (intervention group, $-7.0,95 \%$ confidence interval -8.9 to -5.1 ; control group, $-1.8,-3.5$ to $-0.2: \mathrm{P}<0.0001)$ and coping $(1.0,-0.3$ to $2.3 v$ $-0.4,-1.6$ to $0.8: \mathrm{P}<0.05)$. In adolescents only the subscale catastrophisation showed a significantly greater improvement (table 3).

Quality of life for parents of children aged less than 13 years Improvement in quality of life for parents of children aged 3 months to 7 years was significantly greater in the intervention group for all five subscales of the quality of life questionnaire (table 4). Improvement in quality of life for parents of children aged 8-12 years was significantly greater in the intervention group for three of the five subscales. The improvement in the subscales for confidence in medical treatment, emotional coping,

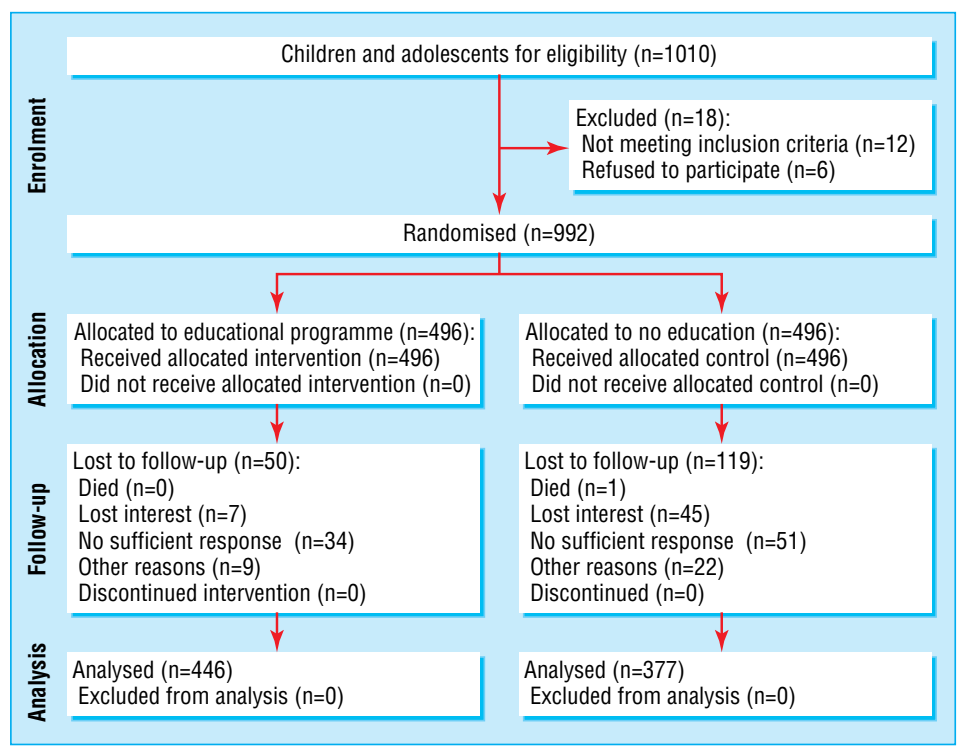

Flow of participants through trial 
Table 3 Outcome variables using analysis of covariance at baseline and 12 months' follow-up for groups receiving an educational programme in atopic dermatitis or no education

\begin{tabular}{|c|c|c|c|c|c|c|c|c|}
\hline \multirow[b]{2}{*}{ Outcome by age group } & \multicolumn{3}{|c|}{ Intervention } & \multicolumn{3}{|c|}{ No intervention } & \multirow{2}{*}{$\begin{array}{c}\begin{array}{c}\text { No intervention minus } \\
\text { intervention }\end{array} \\
\text { Difference }(95 \% \mathrm{Cl})\end{array}$} & \multirow[b]{2}{*}{$P$ value } \\
\hline & Baseline & 12 months & $\begin{array}{c}\text { Mean }(95 \% \mathrm{Cl}) \\
\text { difference }\end{array}$ & Baseline & 12 months & $\begin{array}{c}\text { Mean }(95 \% \mathrm{Cl}) \\
\text { difference }\end{array}$ & & \\
\hline 3 months to 7 years: & \multicolumn{3}{|c|}{$\mathrm{n}=274$} & \multicolumn{3}{|c|}{$n=244$} & & \\
\hline Total severity score & 41.1 (16.6) & $23.7(16.7)$ & $\begin{array}{c}-17.5 \\
(-19.6 \text { to }-15.3)\end{array}$ & $40.6(15.2)$ & $28.4(16.5)$ & $\begin{array}{c}-12.2 \\
(-14.3 \text { to }-10.1)\end{array}$ & $-5.2(-8.2$ to -2.2$)$ & 0.0002 \\
\hline $\begin{array}{l}\text { Objective severity } \\
\text { score* }^{*}\end{array}$ & 32.5 (14.3) & 19.5 (13.9) & $\begin{array}{c}-13.0 \\
(-14.8 \text { to }-11.2)\end{array}$ & $31.4(13.0)$ & $22.6(13.4)$ & $\begin{array}{c}-8.7 \\
(-10.5 \text { to }-7.0)\end{array}$ & $-4.2(-6.8$ to -1.7$)$ & 0.0009 \\
\hline Subjective severity & $8.3(3.8)$ & $4.8(3.4)$ & $-3.3(-3.9$ to -2.8$)$ & $8.3(3.8)$ & $6.1(3.6)$ & $\begin{array}{c}-2.2 \\
(-2.7 \text { to }-1.6)\end{array}$ & $-1.1(-1.9$ to -0.3$)$ & $<0.001$ \\
\hline 8-12 years: & \multicolumn{3}{|c|}{$\mathrm{n}=102$} & \multicolumn{3}{|c|}{$\mathrm{n}=83$} & & \\
\hline Total severity score ${ }^{\star}$ & 41.8 (16.6) & $25.8(17.7)$ & $\begin{array}{c}-16.0 \\
(-20.0 \text { to }-12.0)\end{array}$ & $40.4(15.1)$ & 32.6 (16.5) & $\begin{array}{c}-7.8 \\
(-11.4 \text { to }-4.3)\end{array}$ & $-8.2(-13.6$ to -2.8$)$ & 0.003 \\
\hline $\begin{array}{l}\text { Objective severity } \\
\text { score }^{*}\end{array}$ & $34.0(14.1)$ & $21.7(15.1)$ & $\begin{array}{c}-12.3 \\
(-15.6 \text { to }-8.9)\end{array}$ & $32.5(13.1)$ & $26.9(14.2)$ & $\begin{array}{c}-5.6 \\
(-8.7 \text { to }-2.5)\end{array}$ & $-6.7(-11.2$ to -2.1$)$ & 0.005 \\
\hline Subjective severity & $8.5(3.9)$ & $4.9(2.9)$ & $-3.7(-4.6$ to -2.7$)$ & $8.6(3.5)$ & $7.0(3.8)$ & $\begin{array}{c}-1.6 \\
(-2.5 \text { to }-0.7)\end{array}$ & $-2.1(-3.4$ to -0.8$)$ & $<0.001$ \\
\hline \multicolumn{9}{|l|}{ Itching behaviour } \\
\hline Catastrophisation† & $13.6(8.5)$ & $6.6(6.5)$ & $-7.0(-8.9$ to -5.1$)$ & $13.6(8.2)$ & $11.8(8.6)$ & $\begin{array}{c}-1.8 \\
(-3.5 \text { to }-0.2) \\
\end{array}$ & $-5.2(-7.7$ to -2.7$)$ & $<0.0001$ \\
\hline Coping & $7.7(5.1)$ & $8.8(5.4)$ & $1.0(-0.3$ to 2.3$)$ & $7.6(4.6)$ & $7.2(5.0)$ & $-0.4(-1.6$ to 0.8$)$ & $1.5(-0.3$ to +3.2$)$ & 0.047 \\
\hline 13-18 years: & \multicolumn{3}{|c|}{$\mathrm{n}=70$} & \multicolumn{3}{|c|}{$n=50$} & & \\
\hline Total severity score* & 43.1 (14.7) & $23.4(12.6)$ & $\begin{array}{c}-19.7 \\
(-23.7 \text { to }-15.7)\end{array}$ & 40.4 (13.9) & $35.2(15.2)$ & $\begin{array}{c}-5.2 \\
(-10.5 \text { to } 0.1)\end{array}$ & $-14.5(-21.2$ to -7.9$)$ & $<0.0001$ \\
\hline $\begin{array}{l}\text { Objective severity } \\
\text { score* }^{*}\end{array}$ & $34.4(12.4)$ & $19.5(11.1)$ & $\begin{array}{c}-15.0 \\
(-18.4 \text { to }-11.6)\end{array}$ & 33.4 (12.0) & $28.3(12.0)$ & $\begin{array}{c}-5.1 \\
(-9.5 \text { to }-0.6)\end{array}$ & $-9.9(-15.5$ to -4.3$)$ & $<0.0001$ \\
\hline Subjective severity & $8.9(3.2)$ & $5.8(3.4)$ & $-3.1(-4.1$ to -2.2$)$ & $8.8(3.5)$ & $8.1(4.0)$ & $-1.0(-2.1$ to 0.1$)$ & $-2.1(-3.5$ to -0.7$)$ & $<0.0022$ \\
\hline \multicolumn{9}{|l|}{ Itching behaviour } \\
\hline Catastrophisation† & $16.6(7.9)$ & $9.8(8.1)$ & $-6.8(-8.6$ to -5.0$)$ & $16.9(8.6)$ & $14.9(9.0)$ & $\begin{array}{c}-2.0 \\
(-3.9 \text { to }-0.2)\end{array}$ & $-4.7(-7.3$ to -2.2$)$ & 0.0002 \\
\hline Coping & $15.4(7.8)$ & $15.2(8.2)$ & $-0.2(-1.9$ to 1.5$)$ & $14.0(7.0)$ & $14.5(7.0)$ & $0.4(-1.2$ to 2.1$)$ & $-0.6(-3.0$ to +1.7$)$ & 0.875 \\
\hline
\end{tabular}

${ }^{*}$ Scoring of atopic dermatitis scale.

†Negative thoughts on pain that have got out of control.

and acceptance of the disease were significantly greater in the intervention group (table 4). The subscales for psychosomatic wellbeing and effects on social life did not differ significantly between the intervention and control groups (table 4).

\section{Discussion}

Age related educational programmes for the control of atopic dermatitis in children and adolescents are significantly more effective in the long term management of the disease than is conventional treatment. Over a 12 month period statistically significant benefits were seen in the intervention groups for severity of eczema, subjective severity, and effect on parents' quality of life. One important feature of our study was the inclusion of a control group, since improvements in outcomes are also observed in the absence of parental or patient education. The educational intervention is probably complex as it can have a range of specific and non-specific effects and interactions between such effects. The benefit may not be attributable solely to the educational interventions in the absence of a controlled group that has simple non-directive group work with no educational programme. We assumed that patients in the control

Table 4 Results using analysis of covariance of parental quality of life questionnaire at baseline and 12 months for groups receiving an educational programme in atopic dermatitis or no education

\begin{tabular}{|c|c|c|c|c|c|c|c|c|}
\hline \multirow[b]{2}{*}{ Outcome by age group } & \multicolumn{3}{|c|}{ Intervention } & \multicolumn{3}{|c|}{ No intervention } & \multirow{2}{*}{$\begin{array}{c}\text { No intervention } \\
\text { minus intervention } \\
\begin{array}{c}\text { Difference (95\% } \\
\text { Cl) }\end{array}\end{array}$} & \multirow[b]{2}{*}{$P$ value } \\
\hline & Baseline & 12 months & $\begin{array}{l}\text { Mean }(95 \% \mathrm{Cl}) \\
\text { difference }\end{array}$ & Baseline & 12 months & $\begin{array}{l}\text { Mean }(95 \% \mathrm{Cl}) \\
\text { difference }\end{array}$ & & \\
\hline 3 months to 7 years: & & $\mathrm{n}=274$ & & & $\mathrm{n}=244$ & & & \\
\hline Psychosomatic wellbeing & $29.3(7.6)$ & $33.7(7.0)$ & 4.4 (3.6 to 5.2) & $29.1(7.7)$ & $32.1(7.1)$ & $3.1 \quad(2.2$ to 3.9$)$ & 1.4 (0.2 to 2.5$)$ & 0.0040 \\
\hline Effects on social life & $24.9(4.0)$ & $26.7(3.4)$ & 1.8 (1.4 to 2.3$)$ & $24.5(4.4)$ & 25.5 & 1.0 (0.6 to 1.5$)$ & 0.8 (0.2 to 1.4$)$ & $<0.0001$ \\
\hline $\begin{array}{l}\text { Confidence in medical } \\
\text { treatment }\end{array}$ & $16.0(4.0)$ & $20.0(3.5)$ & 4.0 (3.5 to 4.5$)$ & $15.8(4.4)$ & $17.8(4.2)$ & 1.9 (1.4 to 2.4$)$ & 2.1 (1.4 to 2.8$)$ & $<0.0001$ \\
\hline Emotional coping & $13.7(3.2)$ & $16.8(2.9)$ & 3.1 (2.7 to 3.5$)$ & $14.2(3.4)$ & 15.4 & 1.1 (0.7 to 1.6$)$ & 1.9 (1.3 to 2.5$)$ & $<0.0001$ \\
\hline Acceptance of disease & $7.1(1.9)$ & $8.2(1.7)$ & $1.1(0.8$ to 1.3$)$ & $7.0(1.9)$ & $7.5(1.8)$ & 0.5 (0.3 to 0.8$)$ & $0.6(0.2$ to 0.9$)$ & $<0.0001$ \\
\hline 8-12 years: & & $n=102$ & & & $n=83$ & & & \\
\hline Psychosomatic wellbeing & $31.5(7.9)$ & $34.7(6.0)$ & 3.2 (1.9 to 4.5$)$ & $31.2(6.1)$ & $33.8(7.0)$ & 2.6 (1.4 to 3.8$)$ & $0.6(-1.2$ to 2.4$)$ & 0.360 \\
\hline Effects on social life & $25.8(4.2)$ & $27.0(3.8)$ & $1.1(0.4$ to 1.8$)$ & $26.3(4.0)$ & $27.2(3.5)$ & 0.9 (0.2 to 1.6$)$ & $0.2(-0.8$ to 1.2$)$ & 0.940 \\
\hline $\begin{array}{l}\text { Confidence in medical } \\
\text { treatment }\end{array}$ & $17.0(4.0)$ & $20.1(3.2)$ & 3.1 (2.2 to 3.9$)$ & $17.4(3.9)$ & $17.5(4.4)$ & $0.1(-0.7$ to 1.0$)$ & $2.9(1.7$ to 4.1$)$ & $<0.0001$ \\
\hline Emotional coping & $13.7(3.3)$ & $16.4(2.8)$ & 2.7 (2.0 to 3.4$)$ & $14.7(3.2)$ & $15.6(3.4)$ & 0.9 (0.2 to 1.6$)$ & 1.8 (0.9 to 2.8$)$ & 0.002 \\
\hline Acceptance of disease & $7.3(1.9)$ & $8.1(1.5)$ & 0.8 (0.4 to 1.2$)$ & $7.4(1.7)$ & $7.7(1.8)$ & $0.2(-0.2$ to 0.6$)$ & 0.6 (0 to 1.2$)$ & 0.031 \\
\hline
\end{tabular}


groups were highly motivated and tried to optimise their therapies. Any treatment interventions were not restricted in either intervention or control groups. We monitored treatments by questionnaire and found no major imbalances between study arms. The effect of education on long term improvements of disease severity was noticeable and compares favourably with the improvement in disease management achievable by drug intervention alone.

It is well known that patients with an identical composite score on the scoring of atopic dermatitis scale may differ greatly in the measures of individual items. To our knowledge, however, even a 5 point improvement in the score might be clinically relevant for an individual patient.

The design of the programme, developed by the German atopic dermatitis intervention study, differs from previous psychosocial interventions. The educational programme comprises a 40 hour training workshop for teachers qualified in atopic dermatitis. The programme is offered by institutions with national certification for the education of children and adolescents with the disease. A facility that provides education in atopic dermatitis must have at least one certified trainer, as well as further team members, for the programme to be correctly administered by doctors and psychologists, in combination with nutritionists or dietitians. One new and notable aspect of the educational programme is the promotion of cooperation between different professionals, despite the highly diverse approaches of the different disciplines.

In Germany, although almost all established inpatient departments specialising in atopic dermatitis offer patient education, the ideal situation is one in which educational facilities are associated with a college that has long term experience in patient education and is able to offer supervision and instructed seminars (so called "train the trainer" workshops). In 2000 the Association for Atopic Eczema Education established eight colleges in Germany to fulfil these needs.

Our study expands on the positive results seen with adult educational programmes ${ }^{17-19}$ and shows that such an approach works well in the control of atopic dermatitis in children and adolescents. Our results support those observed in previous single centre studies with smaller numbers of patients, which showed a beneficial effect of education in children with atopic dermatitis and their parents. ${ }^{720}$ In particular, Staab et al showed that parents' quality of life improved significantly in the intervention groups compared with a control group, using a programme that provided the basis for the intervention presented here. ${ }^{21}$

A strategy that maximises patient and parent education can complement a symptom oriented therapeutic approach. ${ }^{22}$ Such an approach is appropriate for atopic dermatitis, when psychological and nutritional factors and a combination of topical and systemic therapies may need to be considered to tackle the underlying multifactorial pathophysiology of this chronic disease ${ }^{23}$ In addition to treating the symptoms of atopic dermatitis in childhood and adolescence, giving parents educational support is an important factor in achieving a positive long term outcome. $^{12}$

Although the value of programmes for the prevention of atopic dermatitis is recognised, this approach is usually used when basic therapy and expert medical attention have failed, and is not used as a primary means of disease management. We included in our study only families of children diagnosed as having moderate to severe atopic dermatitis $(>20$ on scoring of atopic dermatitis scale). However a study that evaluated educating adult patients about atopic dermatitis showed that those patients with less severe symptoms derived greater
What is already known on this topic

Atopic dermatitis is a chronic skin disease with a high prevalence and high burden

Lack of information and lack of confidence in medical treatment lead to suboptimal management of the disease

What this study adds

Age related educational programmes improve the long term management of atopic dermatitis

Both parents of affected young children and adolescents reported reduced severity of eczema and improved quality of life

benefit. ${ }^{24}$ Future studies should tackle the target groups that would benefit most from education.

In conclusion we found that age related educational programmes for the control of atopic dermatitis in children and adolescents are significantly more effective in the long term management of the disease than is conventional treatment. Such programmes should be considered for integration into routine care.

Contributors: DS was study coordinator. She was responsible for the educational programme in one of the study centres and was involved in the study design, evaluation of the instruments, and development of the programme. TLD was responsible for the evaluation centre and data management, was involved in the study design, evaluation of the instruments, and the development of the medical content of the programme, and wrote the paper with UG and DS. MF was responsible for one of the study centres and was involved in the development of the medical content of the programme. $\mathrm{JK}$ was involved in the development and testing of the evaluation instruments. TL-C was involved in the development of the child educational part of the programme. JR was responsible for one of the study centres and was involved in the development of the medical content of the programme. SS was responsible for the inpatient study centre and was mainly involved in the development of the adolescent part of the programme and didactic topics. RS was involved in the study design, data management, and evaluation. GS-O was involved in the development of the psychological content of the programme and in the evaluation. CS was responsible for the educational programme in one of the study centres and was involved in the development of the medical content of the programme. RSch was responsible for one of the study centres and was involved in the development of the medical content of the programme. TW was responsible for one of the study centres and was involved in the development of the medical content of the programme and the didactic presentation of the manuals. MW was responsible for the educational programme in one of the study centres and was involved in the didactic development of the programme. UW was principal investigator, initiated the proposal and was involved in the study design. UG was involved in the study design and was head of the evaluation group. All authors approved the final draft. DS, TLD, MF, JR, RSch, TW, and UG are guarantors.

Funding: German Federal Ministry of Health and Social Services (grant No 01GL0010).

Competing interests: None declared.

Ethical approval: Ethics committee of the Humboldt University, Berlin.

Williams HC, Robertson CF, Stewart AW on behalf of the ISAAC Steering Committee Worldwide variations in the prevalence of atopic eczema symptoms. J Allergy Clin Immunol 1999;103:125-38.

2 Diepgen TL. Is the prevalence of atopic dermatitis increasing? In: Williams HC, ed Epidemiology of atopic eczema. Cambridge: Cambridge University Press, 2000:96-109.

Fivenson D, Arnold RJ, Kaniecki DJ, Cohen JL, Frech F, Finlay AY. The effect of atopic dermatitis on total burden of illness and quality of life on adults and children in a large dermatitis on total burden of illness and quality of life on adults
managed care organization. J Manag Care Pharm 2002;8:333-42.

4 Williams RB, Schneiderman N. Psychosocial interventions can improve clinical outcomes in organic disease. Psychosom Med 2002;64:552-7.

5 Warsi A, Wang PS, LaValley MP, Avorn J, Solomon DH. Self-management education programs in chronic disease: a systematic review and methodological critique of the literature. Arch Intern Med 2004;164:1641-9. 


\section{Research}

6 Guevara JP, Wolf FM, Grum CM, Clark NM. Effects of educational interventions for self management of asthma in children and adolescents: systematic review an meta-analysis. BMJ 2003;326:1308-9.

7 Broberg A, Kalimo K, Lindblad B, Swanbeck G. Parental education in the treatment of childhood atopic eczema. Acta Derm Venereol 1990;70:495-9.

8 Gebert N, Hummelink R, Konning J, Staab D, Schmidt S, Szczepanski R, et al. Efficacy of a self-management program for childhood asthma-a prospective controlled study. Patient Educ Couns 1998;35:213-20.

9 Hanifin J, Rajka G. Diagnostic features in atopic dermatitis. Acta Dermatovenerol 1980;(suppl 92):44-7.

10 The European Task Force on Atopic Dermatitis. Severity scoring of atopic dermatitis: the SCORAD index. Consensus Report of the European Task Force on Atopic Dermatitis. Dermatology 1993;186:23-31.

11 Cohen J. Statistical power analysis for the behavioural sciences. 2nd ed. Hillsdale, NJ Lawrence Erlbaum, 1988.

12 Wenninger K, Kehrt R, von Ruden U, Lehmann C, Binder C, Wahn U, et al. Structured parent education in the management of childhood atopic dermatitis: the Berlin model. Patient Educ Couns 2000;40:253-61.

13 Clausen K, Ciesla R, Köhnlein B, Schon M, Wenninger K, Werfel T. Methods and didactic of atopic dermatitis school. Prävention und Rehabilitation 1998;4:198-202.

14 Lob-Corzilius T, Böer S, Scheewe S, Wilke K, Schon M, Schulte im Walde J, et al. The skin detective as a survey tool for self-assessment in the context of training for patients with atopic dermatitis. Dermatol Psychosom 2004;5:141-6.

15 Kupfer J, Keins P, Brosig B, Diepgen T, Fartasch M, Korsch E, et al. Development of questionnaires of coping with disease and itching cognitions for children and adolescents with atopic eczema. Dermatol Psychosom 2003;4:79-85.

16 Von Rüden U, Kehrt R, Staab D, Wahn U. Development and validation of a disease specific questionnaire on quality of life of parents of children with atopic dermatitis. $Z F$ Gesundheitswiss 1999;4:335-50

17 Riemsma RP, Taal E, Kirwan JR, Rasker JJ. Patient education programmes for adults with rheumatoid arthritis. BMJ 2002;325:558-9.

18 Weingarten SR, Henning JM, Badamgarav E, Knight K, Hasselblad V, Gano A Jr, et al Interventions used in disease management programmes for patients with chronic illness-which ones work? Meta-analysis of published reports. BMJ 2002;325:925.

19 Fox C, Kilvert A. Intensive education for lifestyle change in diabetes. $B M$ J 2003:327:1120-1.

20 Chinn DJ, Poyner T, Sibley G. Randomized controlled trial of a single dermatology nurse consultation in primary care on the quality of life of children with atopic eczema. BrJ Dermatol $2002 \cdot 146: 432-9$.

21 Staab D, von Rueden U, Kehrt R, Erhart M, Wenninger K, Kamtsiuris P, et al. Evaluation of a parental training program for the management of childhood atopic dermatitis. Pediatr Allergy Immunol 2002;13:84-90.

22 American Academy of Dermatology. Guidelines of care for atopic dermatitis. J Am Acad Dermatol 1992;26(3 Pt 2):485-8.

23 Ellis C, Luger T, Abeck D, Allen R, Graham-Brown RA, De Prost Y, et al. Internationa consensus conference on atopic dermatitis II (ICCAD II): clinical update and current treatment strategies. Br J Dermatol 2003;148(suppl 63):3-10.
24 Ehlers A, Stangier U, Gieler U. Treatment of atopic dermatitis: a comparison of psychological and dermatological approaches to relapse prevention. J Consult Clin Psychol 1995;63:624-35.

(Accepted 9 March 2006)

bmj.com 2006;332:933

Department of Paediatric Pulmonology and Immunology, Charité, Humboldt University, Berlin

Doris Staab paediatric allergologist

Ulrich Wahn professor

Department of Clinical Social Medicine, Occupational and Environmental

Dermatology, University Hospital Heidelberg, Thibautstrasse 3, D-69115

Heidelberg, Germany

Thomas L Diepgen professor

Reginald Scheidt epidemiologist

Department of Dermatology, University Erlangen, Germany

Manig Fartasch professor

Department for Medical Psychology, Justus-Liebig-University Giessen, Germany

Jörg Kupfer psychologis

Childrens Hospital Osnabrück, Germany

Thomas Lob-Corzilius paediatric allergologist

Rüdiger Szczepanski paediatric allergologist

Department of Dermatology and Allergy Biederstein, Technical University Munich, Germany

Johannes Ring professor

Christina Schnopp dermatologist

Rehabilitation Clinic for Children and Adolescents, Sylt, Germany

Sibylle Scheewe paediatric allergologist

Department of Psychosomatic Medicine, Hannover Medical School, Germany Gerhard Schmid-Ott professor

Department of Dermatology and Allergology, Hannover Medical School, Germany Thomas Werfel professor

Childrens' Hospital Amsterdamer Strasse, Köln, Germany

Marita Wittenmeier atopic dermatitis trainer

Department of Psychosomatic Medicine and Psychotherapy,

Justus-Liebig-University Giessen, Germany

Uwe Gieler professor

Correspondence to: T L Diepgen thomas_diepgen@med.uni-heidelberg.de 